\title{
Liposarcomas of the posterior mediastinum: clinicopathologic study of 18 cases
}

\author{
Pablo Ortega ${ }^{1}$, David Suster ${ }^{1}$, Giovanni Falconieri ${ }^{2}$, Eduardo Zambrano ${ }^{1}$, Cesar A Moran ${ }^{3}$, \\ Carl Morrison ${ }^{4}$ and Saul Suster ${ }^{1}$ \\ ${ }^{1}$ Department of Pathology and Laboratory Medicine, Medical College of Wisconsin, Milwaukee, WI, USA; \\ ${ }^{2}$ Department of Pathology, Policlinica di Cattinara, Trieste, Italy; ${ }^{3}$ Department of Pathology, M.D. Anderson \\ Cancer Center, Houston, TX, USA and ${ }^{4}$ Department of Pathology, Roswell Park Cancer Center, Buffalo,
} $N Y, U S A$

\begin{abstract}
Sarcomas of the posterior mediastinum are rare and correspond mostly to neurogenic tumors. We studied 18 cases of liposarcoma presenting in the posterior mediastinum; because of their unusual location, some of these tumors posed difficulties for diagnosis. There were 11 men and 7 women aged 29-87 years (mean: 57). The tumors were large lobulated masses ranging from 6 to $30 \mathrm{~cm}$ in greatest diameter (median: $15 \mathrm{~cm}$ ). Symptoms included cough, dysphagia, and chest pain. Four patients were asymptomatic and the tumors were discovered incidentally on chest X-rays. Histologically, $10 / 18$ (55\%) cases were atypical lipomatous tumor/ well-differentiated liposarcoma, one of which harbored a smooth muscle component (lipoleiomyosarcoma); 3/18 (16\%) were de-differentiated liposarcoma, one of which also harbored a smooth muscle component; 3/18 (16\%) were myxoid/round cell liposarcoma; and 2/18 (11\%) were pleomorphic liposarcoma. The cases of well-differentiated liposarcoma were mostly of the sclerosing type; however, five of them also showed prominent myxoid stroma closely resembling myxoid liposarcoma. Immunohistochemistry was performed in selected cases; 4/8 cases tested showed focal positivity for S-100 protein and 5/8 cases showed nuclear positivity for MDM-2. The three cases of myxoid liposarcoma were all negative for MDM2. Both cases of lipoleiomyosarcoma showed positivity for SMA and desmin in the smooth muscle component. FISH was performed in two cases of well-differentiated liposarcoma and high levels of amplification of MDM2 at 12q13-15 were observed; the CHOP translocation at 12q13.1-q13.2 was absent in both cases. Complete surgical excision was performed in 11 cases; however, negative surgical margins were achieved only in four. Clinical follow-up ranging from 1 to 192 months (median 28 months) was available for 13 patients. Two patients with myxoid/round cell liposarcoma died of tumor after 4 months and 3 years, respectively. Both had widely disseminated metastatic disease at the time of death. Six patients $(6 / 10)$ with well-differentiated liposarcoma were alive and well with no evidence of disease (at 4, 7, 12, 15, and 25 months) and three (3/10) were alive with disease (at 3, 4, and 6 months). One patient with well-differentiated liposarcoma had multiple recurrences and a liver metastasis after 14 years; however, the patient was alive and well at 16 years. Five patients were lost to follow-up. In general, the biologic behavior of liposarcomas in the posterior mediastinum seems to correlate well with the histologic subtype and mirrors that of their counterpart in the retroperitoneum.
\end{abstract}

Modern Pathology (2015) 28, 721-731; doi:10.1038/modpathol.2014.152; published online 5 December 2014

Sarcomas arising in the posterior mediastinum are rare and the majority corresponds to tumors of neurogenic origin. ${ }^{1,2}$ Liposarcomas, in particular, are quite rare in this location and have been mostly the subject of case reports and a few small series. In

Correspondence: Dr S Suster, MD, Department of Pathology, Medical College of Wisconsin, 9200 West Wisconsin Avenue, Milwaukee, WI 53226, USA.

E-mail: ssuster@mcw.edu

Received 9 June 2014; revised 15 September 2014; accepted 15 September 2014; published online 5 December 2014
1927, Edwards ${ }^{3}$ described the first case of posterior mediastinal liposarcoma; since then, $\sim 40$ cases of posterior mediastinal liposarcomas have been described in the English literature. ${ }^{4-18}$ Many of the previously reported cases were described as part of large studies on mediastinal sarcomas before the advent of modern immunohistochemical (IHC) and molecular techniques. A few cases have been reported in the more recent literature based on modern diagnostic criteria and, in some instances, supported by ancillary studies. We have studied the clinicopathologic features of 18 cases of liposarcoma 
arising in the posterior mediastinum. The majority of the cases corresponded to well-differentiated liposarcomas; however, some of the cases in this series showed features of pleomorphic, de-differentiated, and myxoid/round cell liposarcoma. Awareness of the various morphologic manifestations of liposarcoma in the posterior mediastinum is of importance for proper diagnosis and management of these patients. The results of our findings are presented along with a review of the literature.

\section{Materials and methods}

Eighteen cases accessioned under the diagnosis of liposarcoma of the posterior mediastinum were retrieved from the surgical pathology files of the Medical College of Wisconsin, Milwaukee, WI, USA; the Department of Pathology, University of Texas M.D. Anderson Cancer Center, Houston, TX, USA; the Department of Pathology, Udine General Hospital, Udine, Italy; and from the consultation files of two of the authors (CAM, SS). Clinical histories and follow-up information was obtained from the patients' charts or by contacting directly the responsible physicians. The study was conducted with approval of the MCW Institutional Review Board (IRB).

From 3 to 12 hematoxylin and eosin-stained glass slides were available for review from each case. Representative paraffin blocks or unstained slides were available for IHC studies in eight cases. The cases were categorized according to the latest World Health Organization criteria. ${ }^{19}$ Tissue sections were stained in a Dako autostainer using Dako polymer detection. Heat-induced epitope retrieval was applied as pretreatment for the different markers. The antibodies used included MDM2 (Zymed, IF2; 1:100), S-100 protein (Cell Marque; 1:1500), smooth muscle actin (Dako, 1A4; 1:500), and desmin (Dako, D33; 1:75). The chromogen, diaminobenzidine, was utilized for antigen localization. Appropriate positive and negative controls were run concurrently for all the markers tested.

Fluorescent in situ hybridization (FISH) for MDM2 amplification at $12 q 15$ was performed in two cases (2 and 7) using bacterial artificial chromosome RP1161102 (ntLocus 12:67,478.946-67,629,524: NCBI build 35.1 ) that was positive by polymerase chain reaction for exon 1 and 11 of this gene. RP11-61102 was labeled with spectrum orange using commercially available reagents as per the manufacturer's recommendations (Vysis, Downers Grove, IL, USA). A commercially available probe for the centromeric region of chromosome 12 (CEP12; Vysis) labeled with spectrum green was co-hybridized with RP11-61102 for ploidy enumeration. FISH slides were prepared as previously described. ${ }^{18} \mathrm{~A}$ ratio of the total number of RP11-61102 signals to the total number of CEP12 signals, in at least 60 interphase nuclei with nonoverlapping nuclei in the tumor cells, was determined. Validation of the cutoff values of normal ratio scores for RP11-611O2 CEP12 was carried out by scoring 200 nuclei from 40 0.6-mm cores that represented normal tissue from 10 different organs. Tumor cells displaying at least two centromeric chromosome 12 signals and multiple
RP11-611O2 signals, with a RP11-61102/CEP12 ratio $\ddagger 1+2$ times the SD of the normal values were considered consistent with amplification of the MDM2 gene. Values less than the cutoff were consistent with no amplification. Tumor cells displaying multiple CEP12 signals and an approximately equal number of RP1161102 signals with a somewhat random distribution of both were considered polysomy 12 but negative for amplification. FISH for C/EBP homologous protein (DDIT3) translocation at 12q13.1-q13.2 was carried out using a commercially available break-apart probe (Vysis). Validation of the cutoff values of false break-apart signals was carried out by scoring 200 nuclei from 40 0.6-mm cores that represented normal tissue from 10 different organs. Tumor cells displaying at least twice the SD of the normal values were considered consistent with translocation of the DDIT3 (formerly known as CHOP) gene. Evaluation of the DDIT3 gene was carried out using the same probe design in a manner analogous to that for MDM2.

\section{Pathologic Findings}

Clinical findings. Eighteen cases of liposarcoma of the posterior mediastinum with no previous clinical history of soft tissue tumor elsewhere, and with no evidence of tumor in another location on postoperative clinical and radiographic examinations were studied (Table 1). Eleven patients were men and seven were women. The patients' age at the time of diagnosis ranged from 29 to 87 years (median: 57). The most common clinical symptoms were cough, dysphagia, and chest pain; however, in four patients the tumors were asymptomatic despite their large size and were discovered incidentally on radiologic examination. Imaging studies were performed in all patients. The most frequent finding on chest X-rays was obliteration of the hemidiaphragm on the left side. Computerized tomography scans were performed in four patients and showed low-density signal in three cases, and mixed density in one.

Treatment modalities. Complete surgical excision was attempted in 12 patients; negative margins were only achieved in 4. Four patients received postoperative radiation therapy because of positive margins. At the time of surgical resection, most of the tumors were adherent to the diaphragm, esophagus, pericardium, and pleura, and in three cases the tumor also extended into the middle and anterior mediastinal compartments. Information about surgical margin status was unknown in 10 cases. An exploratory thoracotomy in two patients disclosed unresectable tumors due to involvement of vital structures; one of them received radiotherapy and died 4 months after surgery with extensive local disease; the other patient was lost to follow-up. Clinical follow-up was not available in four additional cases. None of the patients in our study was treated with chemotherapy. 
Table 1 Clinicopathologic features in 18 patients with liposarcoma of the posterior mediastinum

\begin{tabular}{|c|c|c|c|c|c|c|c|}
\hline Case & Sex/age & Clinical presentation & Size/gross & Histology & IHC/molecular & Treatment & Follow-up \\
\hline 1 & $\mathrm{M} / 87$ & Cough and chest pain & $\begin{array}{l}23 \times 16 \times 8 \mathrm{~cm} \\
\text { Well-circumscribed mass }\end{array}$ & $\begin{array}{l}\text { Well-differentiated (lipoma-like) } \\
\text { liposarcoma with sclerosis }\end{array}$ & N/A & Surgical excision & $\begin{array}{l}\text { Death from } \\
\text { unrelated causes }\end{array}$ \\
\hline 2 & $\mathrm{~F} / 32$ & Cough and dyspnea & $\begin{array}{l}30 \mathrm{~cm} \text { Multilobated, } \\
\text { well-circumscribed mass }\end{array}$ & $\begin{array}{l}\text { Well-differentiated (lipoma-like) } \\
\text { with sclerosis and myxoid areas }\end{array}$ & $\begin{array}{l}\text { MDM2 positive } \\
\text { by FISH }\end{array}$ & $\begin{array}{l}\text { Complete surgical excision } \\
\text { with negative margins }\end{array}$ & A\&W @ 25 mos \\
\hline 3 & $\mathrm{~F} / 50$ & Chest pain & $\begin{array}{l}9 \times 9 \times 4.5 \mathrm{~cm} \text { Multinodular } \\
\text { mass between upper } \\
\text { thoracic spine and esophagus }\end{array}$ & $\begin{array}{l}\text { Well-differentiated liposarcoma } \\
\text { (lipoma-like) with areas of sclerosis, } \\
\text { "inflammatory" components, and myxoid } \\
\text { areas with scattered atypical lipoblastic cells }\end{array}$ & N/A & $\begin{array}{l}\text { Complete surgical excision } \\
\text { with negative margins }\end{array}$ & $\mathrm{A} \& \mathrm{~W} @ 15 \mathrm{mos}$ \\
\hline 4 & $\mathrm{M} / 60$ & $\begin{array}{l}\text { Incidental finding on } \\
\text { CXR, no symptoms }\end{array}$ & $\begin{array}{l}18 \times 10 \times 6 \mathrm{~cm} \text {, } \\
\text { Well-circumscribed and } \\
\text { thinly encapsulated mass }\end{array}$ & $\begin{array}{l}\text { Well-differentiated (lipoma-like) } \\
\text { liposarcoma with foci of sclerosis }\end{array}$ & N/A & Compete surgical excision & $\mathrm{A} \& \mathrm{~W} @ 4 \mathrm{mos}$ \\
\hline 5 & $\mathrm{M} / 59$ & Left flank pain and cough & $\begin{array}{l}20 \times 17 \times 15 \mathrm{~cm} \text {, } \\
\text { Well-circumscribed, lobulated, } \\
\text { and thinly encapsulated mass }\end{array}$ & $\begin{array}{l}\text { Well-differentiated (lipoma-like) liposarcoma } \\
\text { with areas of sclerosis and myxoid areas with } \\
\text { scattered atypical lipoblastic cells }\end{array}$ & N/A & N/A & $\mathrm{A} \& \mathrm{~W} @ 7 \mathrm{mos}$ \\
\hline 6 & $\mathrm{M} / 49$ & $\begin{array}{l}\text { Incidental finding of } \\
\text { CXR, no symptoms }\end{array}$ & $\begin{array}{l}6 \times 5 \times 4 \mathrm{~cm} \text {, Lobulated, } \\
\text { well-circumscribed mass }\end{array}$ & $\begin{array}{l}\text { Well-differentiated (lipoma-like) } \\
\text { liposarcoma with foci of sclerosis }\end{array}$ & $\mathrm{N} / \mathrm{A}$ & Complete surgical excision & $\mathrm{A \& W} @ 12 \mathrm{mos}$ \\
\hline 7 & $\mathrm{M} / 54$ & $\begin{array}{l}\text { Dysphagia and hypodense } \\
\text { mass behind esophagus } \\
\text { on CT scan }\end{array}$ & $\begin{array}{l}8 \times 7.5 \times 4 \mathrm{~cm} \text {, Lobulated, } \\
\text { well-circumscribed mass }\end{array}$ & $\begin{array}{l}\text { Well-differentiated (lipoma-like) } \\
\text { lipsasama with foci of sclerosis }\end{array}$ & $\begin{array}{l}\text { S-100, ACT, and } \\
\text { Des-negative MDM2 } \\
\text { positive by IHC and FISH }\end{array}$ & $\begin{array}{l}\text { Complete surgical excision } \\
\text { with negative margins }\end{array}$ & LFU \\
\hline 8 & $F / 69$ & Cough and dyspnea & $\begin{array}{l}19 \times 15 \times 10 \mathrm{~cm} \text {, Lobulated, } \\
\text { well-circumscribed mass }\end{array}$ & $\begin{array}{l}\text { Well-differentiated (lipoma-like) liposarcoma } \\
\text { with foci of sclerosis, and myxoid areas } \\
\text { with scattered atypical lipoblastic cells }\end{array}$ & N/A & Complete surgical excision & LFU \\
\hline 9 & $\mathrm{M} / 67$ & $\begin{array}{l}\text { Incidental finding on } \\
\text { routine CXR, no symptoms }\end{array}$ & $\begin{array}{l}13 \times 9 \times 5 \mathrm{~cm} \text {, Lobulated, } \\
\text { well-circumscribed mass }\end{array}$ & $\begin{array}{l}\text { Well-differentiated (lipoma-like) liposarcoma } \\
\text { with areas of sclerosis, and focal smooth } \\
\text { muscle differentiation (lipoleiomyosarcoma) }\end{array}$ & $\begin{array}{l}\text { S-100 focally positive, } \\
\text { MDM2 positive by IHC; } \\
\text { ACT and Desm positive in } \\
\text { smooth muscle component }\end{array}$ & Complete surgical excision & $\begin{array}{l}\text { Multiple local recurrences } \\
\text { with identical morphology } \\
(\times 3) \text { and mets to the } \\
\text { liver after } 14 \text { years-A\&W } \\
\text { @ } 192 \text { mos }\end{array}$ \\
\hline 10 & $\mathrm{M} / 48$ & $\begin{array}{l}\text { Incidental finding on } \\
\text { CXR, no symptoms }\end{array}$ & $\begin{array}{l}6 \times 5.5 \times 4.5 \mathrm{~cm} \text { Ovoid, } \\
\text { well-circumscribed, and } \\
\text { thinly encapsulated mass }\end{array}$ & $\begin{array}{l}\text { Well-differentiated (lipoma-like) liposarcoma } \\
\text { with areas of sclerosis, and myxoid areas }\end{array}$ & N/A & Complete surgical excision & LFU \\
\hline 11 & $\mathrm{M} / 63$ & $\begin{array}{l}\text { Upper abdominal pain } \\
\text { with displacement of } \\
\text { esophagus by posterior } \\
\text { mediastinal mass on CT scan }\end{array}$ & $\begin{array}{l}8 \times 6 \times 5 \mathrm{~cm} \text {, } \\
\text { Well-circumscribed mass } \\
\text { adherent to thoracic } \\
\text { aorta and esophagus }\end{array}$ & Pleomorphic liposarcoma & N/A & $\begin{array}{l}\text { Surgical excision with positive } \\
\text { margins + postoperative } \\
\text { radiotherapy }\end{array}$ & AWD @ 4 mos \\
\hline 12 & $\mathrm{~F} / 67$ & $\begin{array}{l}\text { Dysphagia with large mass } \\
\text { displacing the esophagus on } \\
\text { CXR and CT scan }\end{array}$ & $\begin{array}{l}10 \times 5 \times 4 \mathrm{~cm} \text {, Well-circumscribed, } \\
\text { lobulated mass }\end{array}$ & Pleomorphic liposarcoma & N/A & $\begin{array}{l}\text { Surgical excision with positive } \\
\text { margins + postoperative } \\
\text { radiotherapy }\end{array}$ & AWD @ 3 mos \\
\hline 13 & $\mathrm{M} / 75$ & $\begin{array}{l}\text { Weight loss and } \\
\text { dyspnea }\end{array}$ & $\begin{array}{l}14 \times 10 \times 8 \mathrm{~cm} \text { Well-circumscribed } \\
\text { and lobulated mass }\end{array}$ & $\begin{array}{l}\text { Low-grade de-differentiated liposarcoma } \\
\text { with areas of tumor necrosis }\end{array}$ & $\begin{array}{l}\text { S100, SMA, Desm negative; } \\
\text { MDM2 positive (IHC) }\end{array}$ & Complete surgical excision & AWD @ 6 mos \\
\hline 14 & $\mathrm{M} / 66$ & $\begin{array}{l}\text { Chest pain, dysphagia, } \\
\text { and malaise. }\end{array}$ & $\begin{array}{l}9 \times 8 \times 5 \mathrm{~cm} \\
\text { Well-circumscribed mass }\end{array}$ & $\begin{array}{l}\text { Low-grade de-differentiated liposarcoma } \\
\text { with scattered large atypical cells }\end{array}$ & $\begin{array}{l}\text { S100, ACT, Desm negative; } \\
\text { MDM2 positive (IHC) }\end{array}$ & $\begin{array}{l}\text { Complete surgical excision } \\
\text { with negative margins }\end{array}$ & $\mathrm{A} \& \mathrm{~W} @ 24 \mathrm{mos}$ \\
\hline 15 & $\mathrm{~F} / 53$ & $\begin{array}{l}\text { Dysphagia with large } \\
\text { mass displacing esophagus } \\
\text { on CT scan }\end{array}$ & $\begin{array}{l}23 \times 20 \times 12 \mathrm{~cm} \text {, } \\
\text { Lobulated, } \\
\text { well-circumscribed mass }\end{array}$ & $\begin{array}{l}\text { Low-grade de-differentiated liposarcoma } \\
\text { with areas of smooth muscle } \\
\text { differentiation (lipoleiomyosarcoma) }\end{array}$ & $\begin{array}{l}\text { S100 negative, MDM2 positive } \\
\text { (IHC), SMA, and Desm positive } \\
\text { in smooth muscle component }\end{array}$ & Complete surgical excision & LFU \\
\hline 16 & $\mathrm{~F} / 29$ & $\begin{array}{l}\text { Chest pain and } \\
\text { pleural effusion }\end{array}$ & $\begin{array}{l}\text { "Large" inoperable } \\
\text { tumor with metastatic } \\
\text { nodules in parietal pleura }\end{array}$ & $\begin{array}{l}\text { Myxoid/round cell liposarcoma } \\
\text { with predominant round cell } \\
\text { liposarcoma component }\end{array}$ & $\begin{array}{l}\text { S100 positive, MDM2 } \\
\text { negative (IHC); ACT, } \\
\text { Desm negative }\end{array}$ & $\begin{array}{l}\text { Open biopsies; tumor deemed } \\
\text { inoperable, occupied entire } \\
\text { posterior mediastinal } \\
\text { compartment; patient treated } \\
\text { with radiation therapy }\end{array}$ & $\begin{array}{l}\text { DOD @ } 4 \text { mos with mets } \\
\text { to pleura, ovaries, } \\
\text { pituitary, thyroid, pancreas, } \\
\text { and retroperitoneum }\end{array}$ \\
\hline 17 & $\mathrm{M} / 53$ & $\begin{array}{l}\text { Chest pain and } \\
\text { dysphagia }\end{array}$ & $\begin{array}{l}12 \times 8 \times 6 \mathrm{~cm} \text { Irregular } \\
\text { soft tissue mass infiltrating } \\
\text { the right diaphragm }\end{array}$ & $\begin{array}{l}\text { Myxoid/round cell liposarcoma with } \\
\text { predominant round cell liposarcoma } \\
\text { component }\end{array}$ & $\begin{array}{l}\text { S100 positive, MDM2 negative } \\
\text { (IHC), Act, Desm negative }\end{array}$ & $\begin{array}{l}\text { Surgical excision with } \\
\text { positive margins + postoperative } \\
\text { radiotherapy }\end{array}$ & $\begin{array}{l}\text { DOD @ } 3 \text { years with } \\
\text { mets to pleura, lung, } \\
\text { and chest wall }\end{array}$ \\
\hline 18 & $\mathrm{~F} / 54$ & $\begin{array}{l}\text { Left-sided pleuritic chest pain } \\
\text { and left posterior mediastinal } \\
\text { mass on chest X-ray }\end{array}$ & $\begin{array}{l}6 \times 6 \times 5 \mathrm{~cm} \text { Infiltrative } \\
\text { mass wrapping } \\
\text { around the aorta }\end{array}$ & $\begin{array}{l}\text { Myxoid/round cell liposarcoma } \\
\text { with predominant round cell } \\
\text { liposarcoma component }\end{array}$ & $\begin{array}{l}\text { S-100 positive, MDM2 negative } \\
\text { (IHC), Act/Desm negative }\end{array}$ & $\begin{array}{l}\text { Partial resection with positive } \\
\text { margins + postoperative } \\
\text { radiotherapy }\end{array}$ & LFU \\
\hline
\end{tabular}

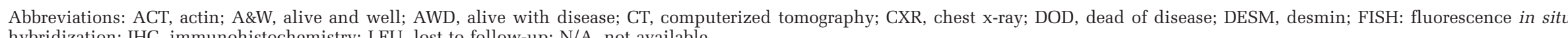
hybridization; IHC, immunohistochemistry; LFU, lost to follow-up; N/A, not available. 


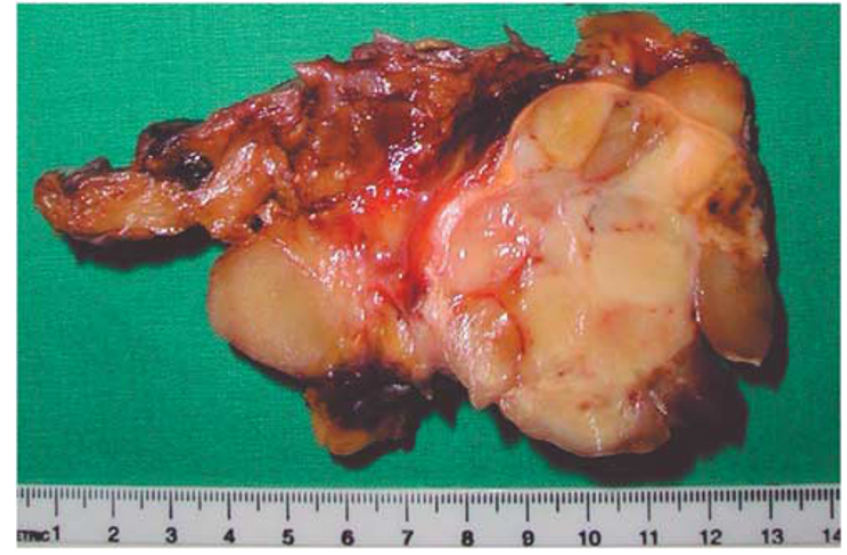

Figure 1 Gross appearance of de-differentiated liposarcoma of posterior mediastinum (Case 13) shows a lobulated mass with yellow, gelatinous cut surface displaying focal areas that appear more solid and rubbery.

Gross features. The tumors ranged in size from 6 to $30 \mathrm{~cm}$ in greatest dimension (median $=15 \mathrm{~cm}$ ). Exact measurements were not available for the inoperable tumor (case 16), which was described as 'large' and occupying the entire posterior mediastinal cavity. Most of the tumors grossly resembled fat, and were multilobulated, well-circumscribed, and with a smooth outer surface covered by a thin fibrous capsule. In eight cases, the tumors showed a myxoid cut surface with focal gelatinous areas. Scattered solid areas were focally seen, particularly in the de-differentiated liposarcoma cases (Figure 1), and foci of necrosis and hemorrhage were also present in the myxoid/round cell and pleomorphic liposarcoma cases.

Microscopic findings. Histologically, the tumors were all characterized by features of adipogenic differentiation.

\section{Well-differentiated liposarcoma/atypical lipoma-} tous tumor. Ten cases (cases 1-10) had features of well-differentiated liposarcoma; all of them contained areas of sclerosis, with fibrous tissue bands of varying thickness that contained scattered spindle cells and large, atypical mononuclear, multinucleated or multilobated tumor cells with lipoblastic features (Figures 2a and b). The areas of sclerosis accounted for $20-30 \%$ of the lesions. No areas of necrosis were found in these tumors. One of the sclerosing cases also showed a prominent inflammatory component made up of sheets and clusters of small lymphocytes admixed with scattered plasma cells (Figure 2c). The non-fibrosing areas were characterized by conventional lipoma-like liposarcoma, with presence of mature, variably sized adipocytes forming lobules separated by thin fibrous septa containing occasional atypical spindle cells and lipoblasts (Figure 2d). Five cases of welldifferentiated liposarcoma were characterized by abundant areas of myxoid stroma that contained scattered lipoblasts and small spindle cells that closely resembled myxoid liposarcoma. The myxoid areas showed thin, branching small vessels with a 'chickenwire' vascular pattern that enhanced the resemblance with myxoid liposarcoma (Figure 3a). Transitions between conventional lipoma-like and sclerosing liposarcoma with areas displaying prominent myxoid stroma were present in all five cases (Figure 3b). In two cases (cases 2 and 5), the myxoid areas also displayed a few scattered pleomorphic lipoblastic cells embedded within the myxoid matrix (Figure 3c). One case of well-differentiated liposarcoma also contained a focus of smooth muscle differentiation (lipoleiomyosarcoma), consisting of fascicles of bland-appearing spindle cells that intersected at right angles (Figure 3d). Mitotic activity and nuclear pleomorphism were minimal in this component.

De-differentiated liposarcoma. Three cases (cases 13-15) showed features of low-grade de-differentiated LPS, characterized by areas of well-differentiated liposarcoma admixed with a non-lipogenic spindle cell component resembling a low-grade spindle cell sarcoma. The de-differentiated component accounted for $20-35 \%$ of the examined sections in all cases. The de-differentiated spindle cell component showed mild to moderate cytologic atypia with low mitotic activity (one to three mitoses per $10 \mathrm{HPF}$ ), and contained occasional larger tumor cells with pleomorphic and multilobated nuclei (Figure 4). One case (case 15) also showed focal areas of smooth muscle differentiation (lipoleiomyosarcoma).

Pleomorphic liposarcoma. Two cases (cases 11 and 12) showed features of pleomorphic liposarcoma and were characterized by scattered bizarre tumor cells with lipoblastic features, including enlarged pleomorphic nuclei with abundant multivacuolated cytoplasm (Figure 5). Areas of necrosis were seen in one case. Mitotic counts varied from $5-10$ per 10 high power fields (HPFs).

Myxoid/round cell liposarcoma. Three cases (cases 16-18) showed features of myxoid liposarcoma with a round cell component. The tumors showed areas characterized by small round to oval, primitiveappearing cells embedded in abundant myxoid stroma and displaying a delicate arborizing capillary vascular network (Figure 6a). Scattered cells with enlarged, pleomorphic nuclei, and vacuolated cytoplasm were also seen, as well as occasional signetring lipoblasts. Dilated spaces resembling distended lymphatics were seen at least focally in all three cases, imparting the characteristic 'pulmonary edema-like' appearance seen in these tumors at other locations (Figure 6b). More densely cellular areas composed of round, hyperchromatic tumor cells corresponding to the round cell liposarcoma component 

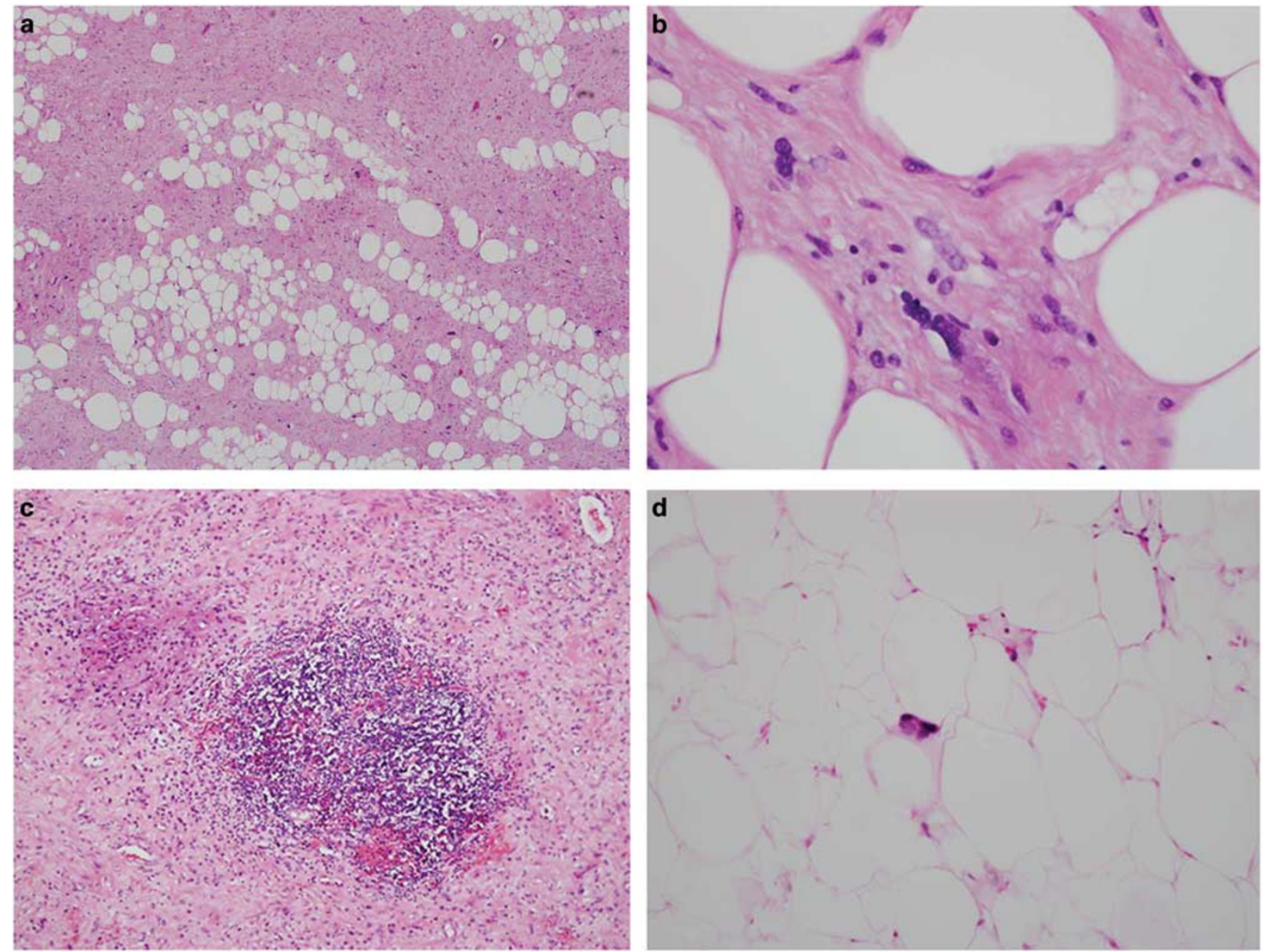

Figure 2 (a) Sclerosing liposarcoma characterized by lobules of adipose tissue alternating with bands of connective tissue containing spindle cells and larger atypical lipoblastic cells (Case 1). (b) Higher magnification of previous field shows atypical spindle cells and multilobated and multinucleated lipoblastic cells embedded in fibroconnective tissue. (c) 'Inflammatory' liposarcoma shows dense lymphoid aggregate within area of fibrosis in otherwise typical well-differentiated liposarcoma (Case 3). (d) Lipoma-like area within welldifferentiated liposarcoma shows mature adipocytes containing scattered atypical, 'floret'-type cells (Case 3).

were present in all three cases (Figure 6c). The round cell component accounted for $20-40 \%$ of these tumors. The tumor cells in these areas formed solid sheets of hyperchromatic round to oval cells with high nuclear to cytoplasmic ratio that were occasionally admixed with signet-ring lipoblasts and contained scattered mitoses (Figure 6d).

\section{IHC Findings}

IHC stains including MDM2 and S-100 were performed in eight cases (cases 7, 9, and 13-18). MDM2 showed scattered nuclear positivity in $5 / 5$ cases of well-differentiated liposarcoma and was negative in all three cases of myxoid liposarcoma. All three cases of low-grade de-differentiated liposarcoma showed scattered nuclear positivity for MDM2 and negative staining for S-100 protein (Figure 7a). Only one of the cases of well-differentiated liposarcoma tested showed focal positivity of the tumor cells for S-100 protein. All three cases of myxoid liposarcoma showed scattered positivity for S-100 protein in the tumor cells (Figure 7b). Both cases of lipoleiomyosarcoma (cases 9 and 15) showed strong positivity of the smooth muscle component for SMA and desmin.

\section{Molecular Studies}

Two cases of well-differentiated liposarcoma (cases 2 and 7) for which adequate histologic materials were available were evaluated by FISH. These cases showed high-level amplification for the MDM2 locus in both cases (Figure 8). More than 50 to 100 RP11-61102 signals and two to five CEP12 signals were seen in virtually all of the neoplastic cells. Interestingly, MDM2 amplification could also be demonstrated in the myxoid liposarcoma-like areas displaying prominent myxoid stroma in one of the cases of well-differentiated liposarcoma (Case 2). The DDIT3 translocation at 12q13.1-q13.2 was absent in both of these cases. 

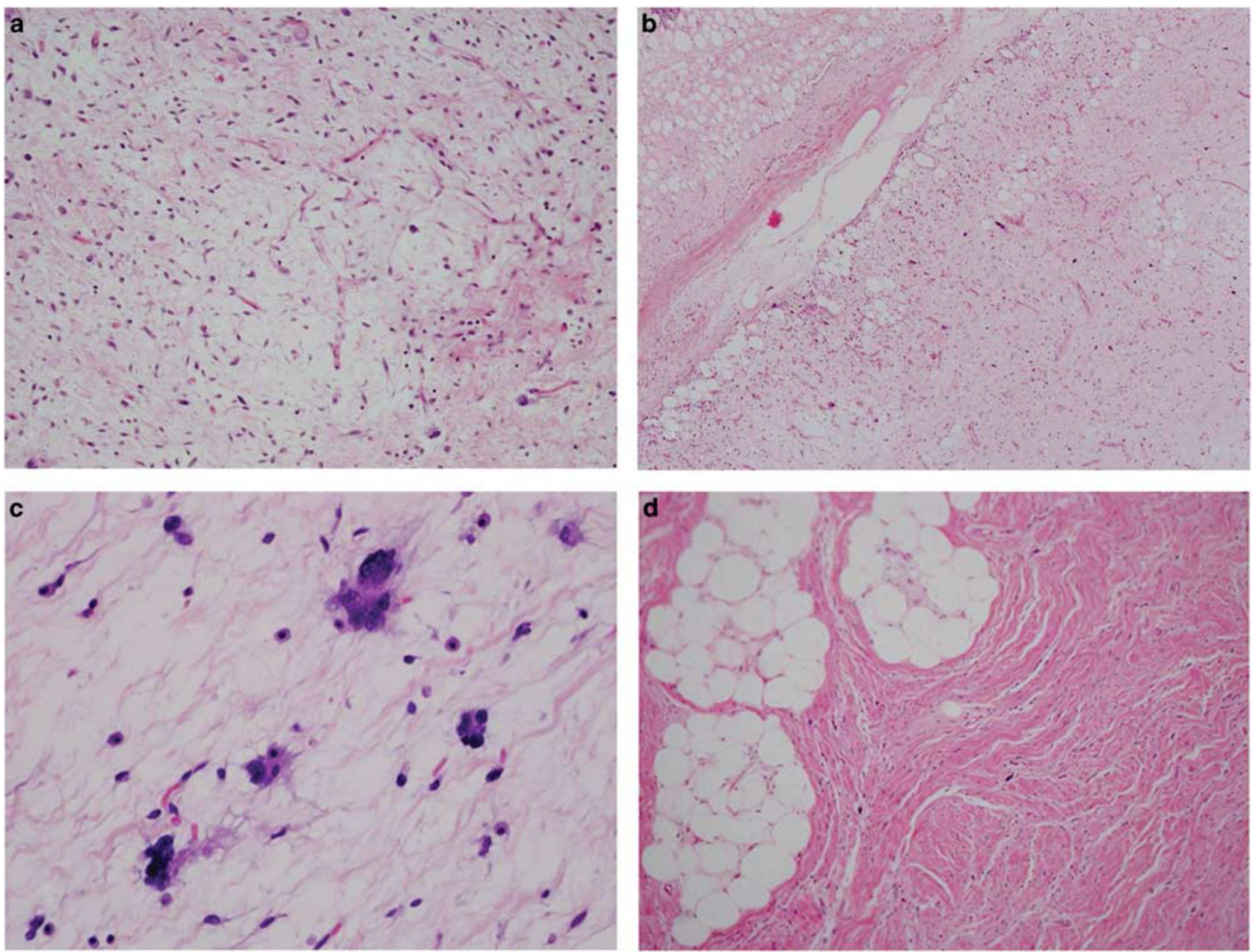

Figure 3 (a) Well-differentiated liposarcoma with prominent myxoid areas is characterized by small round to oval cells embedded in abundant myxoid stroma and containing small branching vessels closely resembling myxoid liposarcoma (case 5). (b) Well-differentiated liposarcoma showing transitions between conventional atypical lipomatous tumor (upper left) and areas displaying prominent myxoid stroma (lower right; Case 5). (c) Well-differentiated liposarcoma with myxoid stroma showing scattered atypical lipoblastic cells (floret cells) (Case 8). (d) Well-differentiated liposarcoma containing area of smooth muscle differentiation (lipoleiomyosarcoma; Case 9).

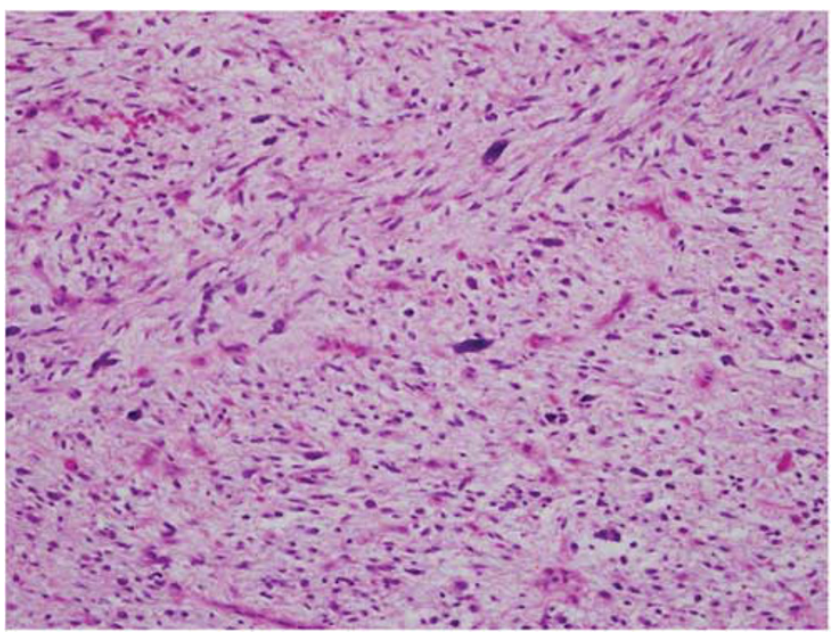

Figure 4 Non-lipogenic component in de-differentiated liposarcoma is characterized by an atypical spindle cell proliferation with mild to moderate atypia and low mitotic activity (Case 13).

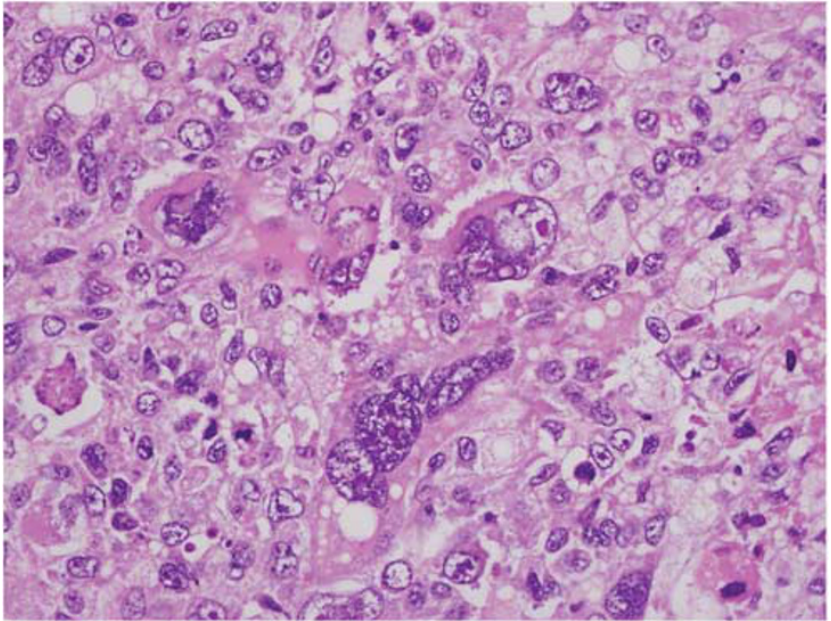

Figure 5 Pleomorphic liposarcoma of posterior mediastinum shows bizarre tumor cells containing large, multinucleated cells with multivacuolated cytoplasm; abundant small intracytoplasmic lipid droplets are seen in many of the tumor cells (case 11). 

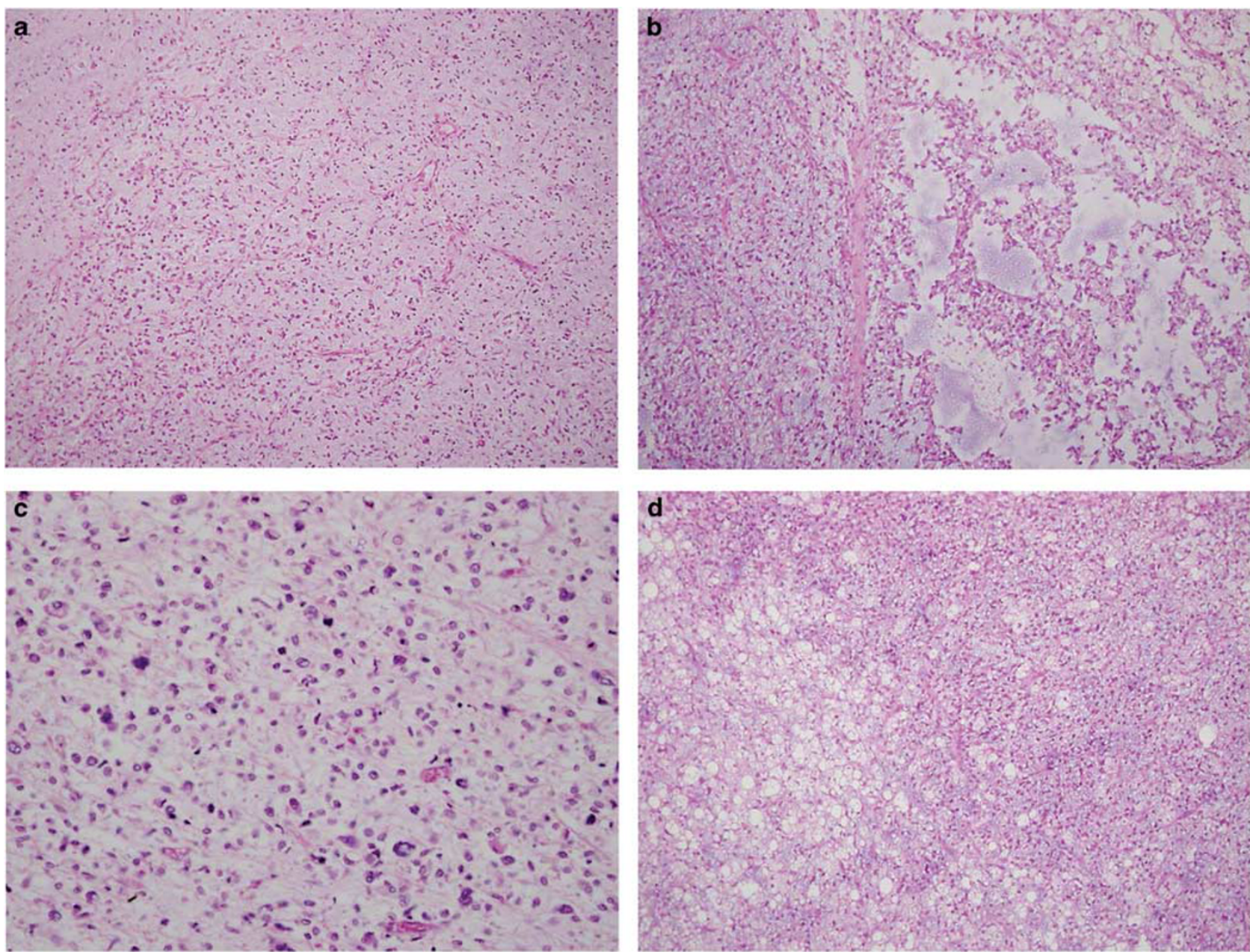

Figure 6 (a) Myxoid liposarcoma showing scattered small round and spindly cells embedded in abundant myxoid matrix and displaying fine arborizing capillary network (Case 16). (b) Myxoid liposarcoma of the mediastinum showing spaces simulating dilated lymphatics (so-called 'pulmonary edema' pattern; Case 16). (c) More solid, densely packed population of cells is seen in the 'round cell' component of the lesion. Notice the cells display a more immature nuclear morphology with scattered mitotic figures (Case 16). (d) Myxoid liposarcoma showing hypercellular areas (right) merging with areas in the left containing abundant signet-ring lipoblasts (Case 16).

\section{Clinical Follow-up}

Clinical follow-up data were available in 13 patients ranging from 1 to 192 months (median=28 months; Table 1). Of these, multiple tumor recurrences were observed in one patient after 65 and 101 months; histologically, the original tumor corresponded to a welldifferentiated liposarcoma with areas of smooth muscle differentiation; the patient developed liver metastases at 14 years but was alive and well at last follow-up (192 months). The last two recurrences were operated on at another hospital and slides were not available for review; as metastases from well-differentiated liposarcoma are extremely rare, the possibility that the recurrence showed evidence of de-differentiation cannot be ruled out. The remainder of patients with well-differentiated liposarcoma was alive at last follow-up from 4 to 25 months (median: 12.6). Six patients (6/10) with well-differentiated liposarcoma were alive and well with no evidence of disease $(4,7,12,15$, and 25 months) and three (3/10) were alive with disease $(3,4$, and 6 months). Three patients died; two patients with myxoid/round cell liposarcoma died due to unresectable and widely metastatic tumors (4 months and 3 years after diagnosis, respectively) and one patient with well-differentiated liposarcoma died of unrelated causes 1 month after surgery (aspiration pneumonia). The two patients with pleomorphic liposarcoma were lost to follow-up after 3 and 4 months following surgery.

\section{Discussion}

Liposarcoma is one of the most common soft tissue sarcomas of adult life; however, it is extremely rare in the mediastinum. ${ }^{1}$ The majority of the studies addressing liposarcomas of the mediastinum to date appear to indicate that these tumors more often occur in the anterior mediastinal compartment. Because of the rarity of liposarcoma in the posterior mediastinum, studies specifically addressing the clinicopathologic features of such tumors in 

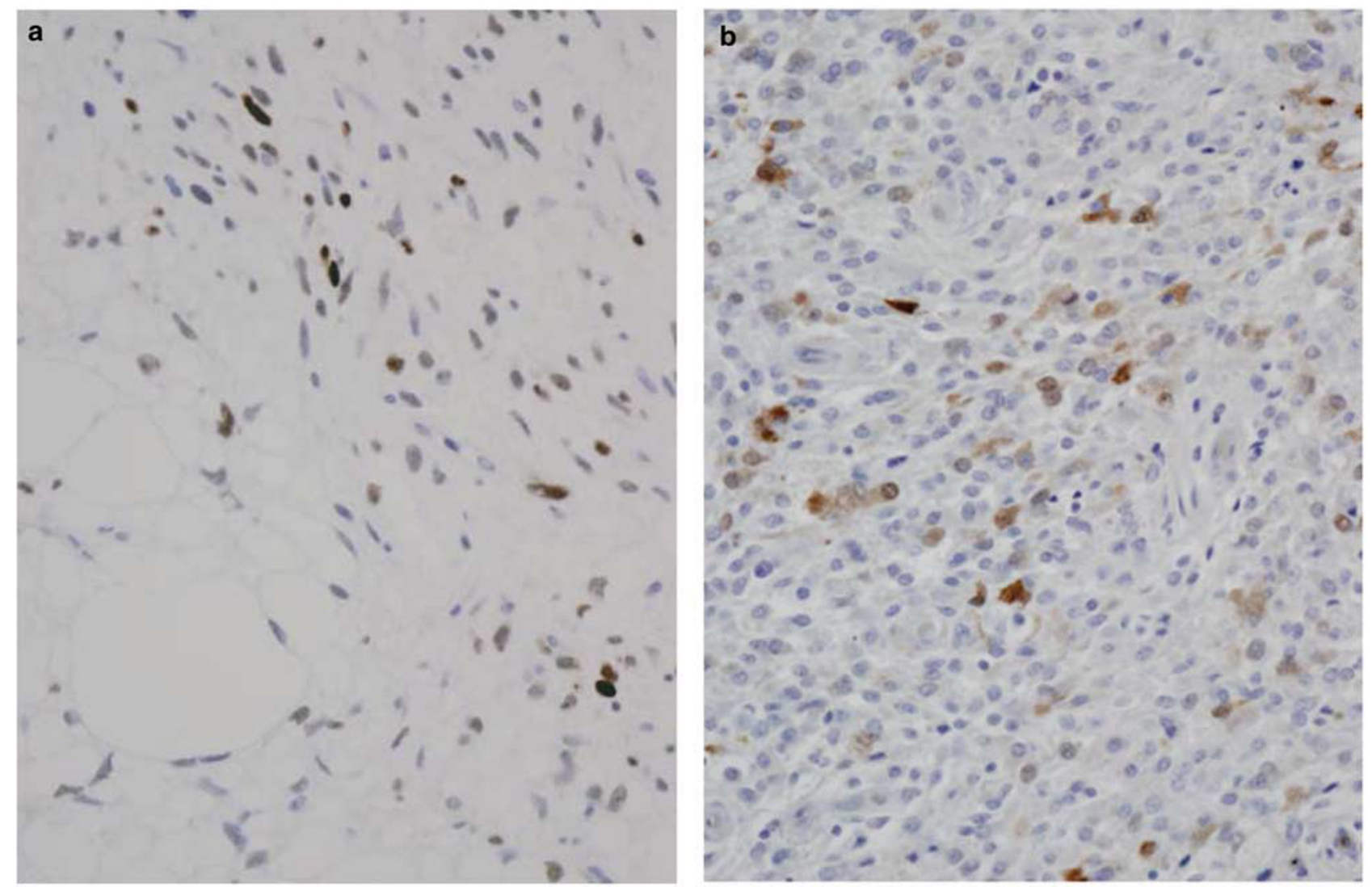

Figure 7 (a) Scattered nuclear positivity for MDM2 is seen in the spindle cell component in de-differentiated liposarcoma (Case 14). (b) Nuclear positivity for S-100 protein is present in scattered cells in the hypercellular portion of a myxoid/round cell liposarcoma (Case 18).

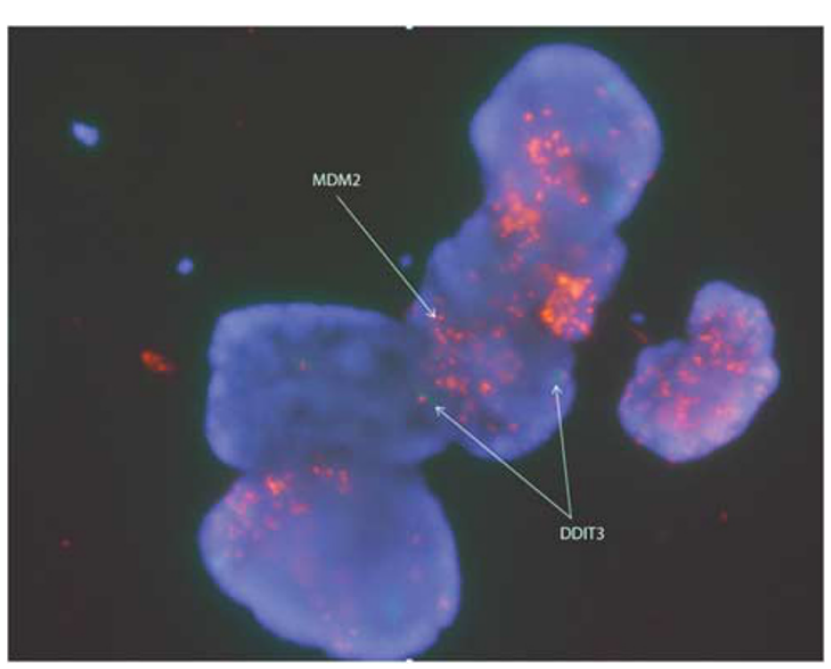

Figure 8 Single color probes used for MDM2 shows high levels of amplification by FISH. Break-apart probes for the DDIT3 locus showed no translocated signals (Case 2).

this particular location have been lacking. Herein, we describe a series of 18 cases of liposarcomas arising in the posterior mediastinum and analyze their clinicopathologic features.

Approximately 40 cases of liposarcoma of the posterior mediastinum have been described in the
English literature $;^{4-18}$ most cases were published before the advent of modern IHC and molecular techniques. A review of the more recent literature (1990-2012) disclosed 24 cases of liposarcoma of the posterior mediastinum. ${ }^{10,12,14,17,18,20-22}$ The patients' ages ranged from 14 to 77 years (median: 49.6), and tumor size varied from 2.2 to $35.6 \mathrm{~cm}$ (median: $17.5 \mathrm{~cm}$ ). Histologically, 12 were diagnosed as well-differentiated liposarcoma, 6 as myxoid, 4 de-differentiated, and 3 pleomorphic. Recurrences were observed in seven patients, whereas metastases were documented only in one case in a patient with pleomorphic liposarcoma. Clinical follow-up was available for 21 patients (median: 24.5 months). At last follow-up, 14/21 were alive (median survival: 25.9 months); $2 / 21$ were alive with disease; and 5/21 died of disease (median survival: 45.8 months).

Diagnosis of de-differentiated liposarcoma in the mediastinum continues to be a challenge and many cases may go unrecognized. Myxoid/round cell liposarcoma also appears to be a very unusual tumor in the posterior mediastinum and, although several cases have been described in the anterior mediastinum, ${ }^{18,22}$ no well-documented cases have been reported so far in the posterior mediastinum. The three cases in our study corresponded to diffusely infiltrative masses with aggressive behavior and 
widespread metastases being documented in two cases.

Tumor location is one of the most important prognostic factors in liposarcomas, as subcutaneous or intramuscular tumors have better survival rates compared with those located in central body cavities. Tumor behavior in the posterior mediastinum appears to be somewhat different from the cases reported in the anterior mediastinum, as the tumors in the latter location appear to be associated with low mortality, recurrence, and metastatic rates. ${ }^{23}$ The first choice of therapy for primary mediastinal liposarcoma is surgical excision; ${ }^{24}$ however, tumors located in central body cavities have the tendency to wrap around vital structures, or they can grossly simulate normal adipose tissue making it very difficult to obtain negative margins. Indeed, in our series, 10 patients underwent complete surgical excision but negative margins were obtained in only four cases.

As in other series, the most common type of mediastinal liposarcoma in our study corresponded to well-differentiated liposarcoma/atypical lipoma $(10 / 18,55 \%)$, followed by de-differentiated $(3 / 18$, $16 \%)$, myxoid $(3 / 18,16 \%)$, and pleomorphic liposarcoma $(2 / 16,11 \%)$. This is relatively similar to the overall distribution of liposarcoma in the retroperitoneum, with the exception of myxoid liposarcoma, which appears to present in the retroperitoneum only as a result of metastatic spread from other sites. Follow-up information showed that the histological type correlated with the clinical behavior of these tumors, similar to liposarcomas at other body cavity locations. All patients with welldifferentiated liposarcoma reported in the recent literature located in the posterior mediastinum were alive at last follow-up (median: 28.6 months) with no recurrence or metastases. ${ }^{18,22}$ Likewise, in our series, all patients with well-differentiated liposarcoma were alive after surgical treatment (median 3.4 years), except for one patient who died of unrelated causes. In one of our cases, however, the patient was alive with disease after a long follow-up period of 16 years and had experienced recurrences on two occasions and developed liver metastasis 14 years after initial diagnosis. This indicates that well-differentiated liposarcoma in the posterior mediastinum can recur and metastasize after a long period of time after initial diagnosis, as is the behavior of similar tumors in other locations. ${ }^{25,26}$

De-differentiated liposarcoma was first described by Evans in $1979^{26}$ and is characterized by an admixture of areas containing well-differentiated liposarcoma with areas of non-lipogenic spindle cell sarcoma. High-grade de-differentiated liposarcoma is the most common pattern and is characterized by an atypical lipomatous tumor that shows areas of cellular, non-lipogenic sarcoma that generally resembles pleomorphic high-grade sarcoma. ${ }^{19}$ These tumors are currently considered less aggressive than other high-grade sarcomas, such as pleomorphic high- grade sarcoma, but are associated with recurrences in $40 \%$ of cases and with distant metastases in up to $20 \%$ of cases. ${ }^{19}$ In the recent literature, cases of dedifferentiated liposarcoma have been reported in all mediastinal compartments and have shared similar clinicopathologic features with those arising in the retroperitoneum. ${ }^{22,27}$ Only four cases of de-differentiated liposarcoma of the posterior mediastinum have been reported before this study; ${ }^{14,18,22}$ the present study contributes three additional cases. Leiomyosarcomatous differentiation is a rare phenomenon that can be found in liposarcomas ${ }^{28,29}$ and is characterized by focal areas of smooth muscle differentiation. The presence of smooth muscle differentiation does not qualify a tumor for a diagnosis of de-differentiated liposarcoma; however, in our series, one case of de-differentiated liposarcoma also showed areas of smooth muscle differentiation in addition to the more conventional areas of low-grade, non-adipogenic spindle cell sarcoma. Another case of conventional well-differentiated liposarcoma without de-differentiation in our series also contained areas of smooth muscle differentiation (lipoleiomyosarcoma).

Myxoid/round cell liposarcoma is a tumor generally located in the extremities, although rarely it can affect central body sites. Myxoid liposarcoma is rarely found in the mediastinum or in the retroperitoneum; therefore, metastatic spread from other sites has to be excluded first in order to make this diagnosis. ${ }^{30}$ The behavior of these tumors will be dependent on their histology; conventional myxoid liposarcoma behaves as a low-grade malignancy, whereas cases characterized by increased cellularity and solid sheets of cells (that is, round cell liposarcoma) can display a highly aggressive behavior. In our study, all three cases of myxoid liposarcoma contained a prominent hypercellular round cell component and displayed aggressive behavior, in two cases leading to death due to tumor with widespread metastases.

To our knowledge, only two cases of pleomorphic liposarcoma of the posterior mediastinum have been reported in the recent literature. ${ }^{18,22}$ One case was described resembling a myxofibrosarcoma but with interspersed lipoblasts; the patient was unfortunately lost to follow-up. ${ }^{22}$ The second case showed aggressive behavior, with recurrence, metastases to bone and soft tissue, and death by tumor at 62 months. ${ }^{18}$ The two cases reported in our study showed features of pleomorphic high-grade sarcoma with numerous atypical lipoblastic cells; the presence of atypical lipoblasts qualified these tumors as pleomorphic liposarcoma. Unfortunately, both patients were lost to follow-up after 3 and 4 months, respectively. It is reasonable to expect, however, that given the high-grade histology, incomplete surgical excision, and the aggressive behavior displayed by similar tumors in other locations that these two patients are also likely to follow an aggressive behavior. 
The main clinical differential diagnosis for posterior mediastinal liposarcomas is with neurogenic tumors, which are the most common mesenchymal neoplasms of the posterior mediastinum. ${ }^{1,31}$ The histologic distinction between neurogenic tumors and lipomatous tumors is generally straightforward, although high-grade lesions and de-differentiated liposarcomas may require use of ancillary techniques for definitive diagnosis. As in other locations, the main histologic differential diagnostic issue for posterior mediastinal liposarcomas actually involves distinguishing a benign lipomatous tumor from well-differentiated liposarcoma, which can sometimes be difficult. IHC or molecular studies to detect amplification for MDM2 can be helpful to make this distinction in difficult lesions, as this marker is generally not expressed in benign lipomatous tumors. ${ }^{32}$ The presence of dense fibrotic zones alternating with the mature adipocytes, with scattered spindle and multinucleated stromal cells with hyperchromatic nuclei and vacuolated cytoplasm corresponding to the lipoblastic cells within the fibrotic areas, is a helpful tip favoring a diagnosis of well-differentiated liposarcoma on routine microscopy. Another problematic area is distinguishing de-differentiated liposarcoma from other spindle cell sarcomas of soft tissue with which they may be confused, including myxofibrosarcoma, solitary fibrous tumor, and others. Attention to the presence of transitions between the non-lipogenic spindle cell component and areas showing frank adipogenic features is of importance; extensive sampling is helpful in identifying such areas, which can be very focal or inconspicuous in these tumors. Awareness of this entity and a high level of suspicion are required when dealing with mediastinal spindle cell sarcomas; use of ancillary techniques such as FISH and immunohistochemistry for MDM2 will be helpful in this setting.

Another important pitfall for diagnosis that was highlighted by our cases is separating well-differentiated liposarcoma with prominent myxoid stroma from true myxoid liposarcomas. A recent study has called attention to the existence of welldifferentiated liposarcomas and de-differentiated liposarcomas that can closely mimic myxoid liposarcoma by virtue of the abundance of myxoid stroma. ${ }^{33}$ Five cases of well-differentiated liposarcoma with myxoid areas were identified in our study. In all cases, areas displaying features of conventional lipoma-like well-differentiated liposarcoma, sclerosing liposarcoma, and 'inflammatory' liposarcoma were also present. A myxoid liposarcoma-like pattern of plexiform vessels was present in the myxoid areas in these tumors, further highlighting the similarity with myxoid liposarcoma. Two cases also showed scattered lipoblastic atypical cells within the myxoid areas, a phenomenon that has been described in liposarcomas in children in whom these tumors have been designated as 'pleomorphic myxoid liposarcoma'. ${ }^{34}$ The lesions differed from pleomorphic myxoid liposarcoma, however, in that they all contained a well-differentiated liposarcoma component. Three cases in our study were initially diagnosed as myxoid liposarcoma but were revised to well-differentiated liposarcoma upon re-review of the histology owing to the identification of areas of conventional liposarcoma. Given the recent recognition of this unusual variant of liposarcoma, it is possible that many cases categorized in the past as 'myxoid liposarcoma' of the mediastinum may have corresponded to this variant. Myxoid liposarcomas are characterized by a unique chromosomal translocation, $\mathrm{t}(12 ; 16)(\mathrm{q} 13 ; \mathrm{p} 11)$, resulting in a fusion of the DDIT3 gene (also known as CHOP or GADD153) on chromosome 12 and the FUS gene (also referred to as TSL) on chromosome $16 . .^{35-37}$ A molecular analysis to find the TSL-CHOP translocation will be of help in establishing a definitive diagnosis. ${ }^{38}$ Adequate material for molecular analysis was available only in one of our cases of well-differentiated liposarcoma with myxoid stroma (case 2); amplification for MDM2 was demonstrated by FISH but the DDIT3 translocation was not detected. Attention to the presence of typical areas of well-differentiated liposarcoma in parts of the tumor can be helpful for properly identifying these lesions. Although no molecular studies were available for any of the three cases of myxoid/round cell liposarcoma in our study, the distinctive histologic features displaying transitions between conventional myxoid liposarcoma and round cell liposarcoma, and the focal S-100 protein positivity and negative staining for MDM2 by immunohistochemistry were sufficient to establish the diagnosis.

In summary, we have described the clinicopathologic features in 18 cases of liposarcoma arising in the posterior mediastinum. It appears that the anterior mediastinum represents a more common location for liposarcomas; however, liposarcomas can also occur in the posterior mediastinum and need to be considered in the differential diagnosis of posterior mediastinal tumors. All histopathologic variants of liposarcoma can be encountered in this location, including well-differentiated, myxoid, dedifferentiated, and pleomorphic liposarcoma. The variegation in patterns and heterogeneity that can be seen in some of these tumors should be taken into account, particularly when evaluating small biopsies of posterior mediastinal tumors. Immunohistochemistry, cytogenetic, or molecular studies may be of assistance for arriving at a correct diagnosis in tumors with unusual features or equivocal morphology.

\section{Disclosure/conflict of interest}

The authors declare no conflict of interest. 


\section{References}

1 Macchiarini P, Ostertag H. Uncommon primary mediastinal tumors. Lancet Oncol 2004;5:107-118.

2 Swanson PE. Soft tissue neoplasms of the mediastinum. Semin Diagn Pathol 1991;8:14-34.

3 Edwards AT. Intrathoracic new growths: an account of seven operable cases. Br J Surg 1927;14:607-628.

4 Munden RF, Nesbitt JC, Kemp BL, et al. Primary liposarcoma of the mediastinum. Am J Roentgenol 2000;175:1340.

5 Pachter MR, Lattes R. Mesenchymal tumors of the mediastinum I. Tumors of fibrous tissue, adipose tissue, smooth muscle, and striated muscle. Cancer 1963;16:74-94.

6 Cicciarelli FE, Soule EH, McGoon DC. Lipoma and liposarcoma of the mediastinum: A report of 14 tumors including one lipoma of the thymus. J Thorac Cardiovasc Surg 1964;47:411-429.

7 Schweitzer DL, Aguam AS. Primary liposarcoma of the mediastinum. Report of a case and review of the literature. J Thorac Cardiovasc Surg 1977;74:83-97.

8 Mikkilineni RS, Bhat S, Cheng AW, et al. Liposarcoma of the posterior mediastinum in a child. Chest 1994; 106:1288-1289.

9 Paci M, De Franco S, Cavazza A, et al. Well-differentiated giant 'lipoma-like' liposarcoma of the posterior mediastinum: a case report. Chir Ital 2003;55:101-104.

10 Marulli G, Rea F, Feltracco P, et al. Successful resection of a giant primary liposarcoma of the posterior mediastinum. J Thorac Oncol 2007;2:453-455.

11 Liu L, Wei X, Pan T. A giant primary myxoid liposarcoma of the posterior mediastinum. Eur J Cardiothorac Surg 2010;37:958.

12 Raghavan R, Raghuram P, Parekh PV, et al. Posterior mediastinal liposarcoma simulating a lung mass: an unusual case report. Cancer Imaging 2007;7:141-144.

13 Dogan R, Ayrancioglu K, Aksu O. Primary mediastinal liposarcoma. A report of a case and review of the literature. Eur J Cardiothorac Surg 1989;3:367-370.

14 Coulibaly B, Bouvier C, Payan MJ, et al. Recurrent dedifferentiated liposarcoma of mediastinum involving lung and pleura. Interact Cardiovasc Thorac Surg 2009;9:741-742.

15 Hirai S, Hamanaka Y, Mitsui N, et al. Surgical resection of primary liposarcoma of the anterior mediastinum. Ann Thorac Cardiovasc Surg 2008;14:38-41.

16 Uner R, Balim AI, Oktem K. Mediastinal liposarcoma. Report of a case. Dis Chest 1963;43:103-105.

17 Mikkilineni RS, Bhat S, Cheng AW, et al. Liposarcoma of the posterior mediastinum in a child. Chest 1994;106:1288-1289.

18 Boland J, Colby TV, Folpe AL. Liposarcomas of the mediastinum and thorax. A clinicopathologic and molecular cytogenetic study of 24 cases, emphasizing unusual and diverse histologic features. Am J Surg Pathol 2012;36:1395-1403.

19 Fletcher CDM, Bridge JA, Hogendoorn PCW, et al. WHO Classification of Tumors of Soft Tissue and Bone, 4th edn. IARC: Lyon; 2013, pp 95-104.

20 Morrison C, Radmacher M, Mohammed N, et al. MYC amplification and polysomy 8 in chondrosarcoma: array comparative genomic hybridization, fluorescent in situ hybridization, and association with outcome. J Clin Oncol 2005;23:9369-9376.

21 Tanaka K, Murota Y, Andoh T, et al. A case of mediastinal liposarcoma surgically removed by bilateral thoracotomy. Kyobu Geka 1997;50:335-337.
22 Hahn HP, Fletcher CD. Primary mediastinal liposarcoma: clinicopathologic analysis of 24 cases. Am J Surg Pathol 2007;31:1868-1874.

23 Klimstra DS, Moran CA, Perino G, et al. Liposarcoma of the anterior mediastinum and thymus. A clinicopathologic study of 28 cases. Am J Surg Pathol 1995;19:782-791.

24 Burt M, Ihde JK, Hajdu SI, et al. Primary sarcomas of the mediastinum: results of therapy. J Thorac Cardiovasc Surg 1998;115:671-680.

25 Weiss SW, Rao VK. Well-differentiated liposarcoma (atypical lipoma) of deep soft tissue of the extremities, retroperitoneum, and miscellaneous sites. A follow-up study of 92 cases with analysis of the incidence of ‘dedifferentiation'. Am J Surg Pathol 1992;16:1051-1058.

26 Evans HL. Liposarcoma: a study of 55 cases with a reassessment of its classification. Am J Surg Pathol 1979;3:507-523.

27 Fabre-Guillevin E, Coindre JM, Somerhausen N, et al. Retroperitoneal liposarcomas: follow-up analysis of dedifferentiation after clinicopathologic reexamination of 86 liposarcomas and malignant fibrous histiocytomas. Cancer 2006;106:2725-2733.

28 Suster S, Wong TY, Moran CA. Sarcomas with combined features of liposarcoma and leiomyosarcoma. Study of two cases of an unusual soft-tissue tumor showing dual lineage differentiation. Am J Surg Pathol 1993;17:905-911.

29 Folpe AL, Weiss SW. Lipoleiomyosarcoma (welldifferentiated liposarcoma with leiomyosarcomatous differentiation): a clinicopathologic study of nine cases including one with dedifferentiation. Am J Surg Pathol 2002;26:742-749.

30 De Vreeze RS, de Jong D, Tielen IH, et al. Primary retroperitoneal myxoid/round cell liposarcoma is a nonexisting disease: an immunohistochemical and molecular biological analysis. Mod Pathol 2009;22:223-231.

31 Reed JC, Hallet KK, Feigin DS. Neural tumors of the thorax: subject review from the AFIP. Radiology 1978;126:9-17.

32 Shimada S, Ishizawa T, Ishizawa K, et al. The value of MDM2 and CDK4 amplification levels using real-time polymerase chain reaction for the differential diagnosis of liposarcomas and their histologic mimickers. Hum Pathol 2006;37:1123-1129.

33 Sioletic S, Dal Cin P, Fletcher CD, et al. Welldifferentiated and dedifferentiated liposarcomas with prominent myxoid stroma: analysis of 56 cases. Histopathology 2013;62:287-293.

34 Alaggio R, Coffin CM, Weiss SW, et al. Liposarcomas in young patients: a study of 82 cases occurring in patients younger than 22 years of age. Am J Surg Pathol 2009;33:645-658.

35 Turc-Carel C, Limon J, Dal Cin P, et al. Cytogenetic studies of adipose tissue tumors. II. Recurrent reciprocal translocation $\mathrm{t}(12 ; 16)(\mathrm{q} 13 ; \mathrm{p} 11)$ in myxoid liposarcomas. Cancer Genet Cytogenet 1986;23:291-299.

36 Sreekantaiah C, Karakousis CP, Leong SP, et al. Cytogenetic findings in liposarcoma correlate with histopathologic subtypes. Cancer 1992;69:2484-2495.

37 Smith TA, Easley KA, Goldblum JR. Myxoid/round cell liposarcoma of the extremities. A clinicopathologic study of 29 cases with particular attention to extent of round cell liposarcoma. Am J Surg Pathol 1996;20:171-180.

38 Panagopoulos I, Mandahl N, Ron D, et al. Characterization of the CHOP breakpoints and fusion transcripts in myxoid liposarcomas with the 12;16 translocation. Cancer Res 1994;54:6500-6503. 